\title{
Conductivity studies on microwave synthesized glasses
}

\author{
ASHA RAJIV ${ }^{1}$, M SUDHAKARA REDDY ${ }^{1}$, R VISWANATHA ${ }^{2}$, JAYAGOPAL UCHIL ${ }^{1}$ and \\ C NARAYANA REDDY ${ }^{3, *}$ \\ ${ }^{1}$ Department of Physics, School of Graduate Studies, Jain University, Bangalore 560027, India \\ ${ }^{2}$ Solid State and Structural Chemistry Unit, Indian Institute of Science, Bangalore 560012, India \\ ${ }^{3}$ Department of Physics, Sree Siddaganga College of Arts, Science and Commerce, Tumkur University, \\ Tumkur 572103, India
}

MS received 27 March 2015; accepted 6 April 2015

\begin{abstract}
Conductivity measurements have been made on $x V_{2} \mathrm{O}_{5}-(100-x)\left[0.5 \mathrm{Na}_{2} \mathrm{O}+0.5 \mathrm{~B}_{2} \mathrm{O}_{3}\right]$ (where $10 \leq x \leq 50)$ glasses prepared by using microwave method. DC conductivity $(\sigma)$ measurements exhibit temperatureand compositional-dependent trends. It has been found that conductivity in these glasses changes from the predominantly 'ionic' to predominantly 'electronic' depending upon the chemical composition. The dc conductivity passes through a deep minimum, which is attributed to network disruption. Also, this nonlinear variation in $\sigma_{\text {dc }}$ and activation energy can be interpreted using ion-polaron correlation effect. Electron paramagnetic resonance (EPR) and impedance spectroscopic techniques have been used to elucidate the nature of conduction mechanism. The EPR spectra reveals, in least modified $\left(25 \mathrm{Na}_{2} \mathrm{O} \mathrm{mol} \%\right)$ glasses, conduction is due to the transfer of electrons via aliovalent vanadium sites, while in highly modified $\left(45 \mathrm{Na}_{2} \mathrm{O}\right.$ mol\%) glasses $\mathrm{Na}^{+}$ion transport dominates the electrical conduction. For highly modified glasses, frequency-dependent conductivity has been analysed using electrical modulus formalism and the observations have been discussed.
\end{abstract}

Keywords. Conductivity; electrical modulus; impedance; microwave; power law; stretched exponent.

\section{Introduction}

Microwave processing of materials is a relatively new technology undergoing rapid developments due to potential advantages and it offers such as reduced processing time, energy efficiency and products with enhanced properties. The only requirement of this method is that at least one of the components used for making glass is microwave active. In recent years many glassy materials have been synthesized as binary or ternary systems using network-forming oxides such as $\mathrm{B}_{2} \mathrm{O}_{3}, \mathrm{P}_{2} \mathrm{O}_{5}, \mathrm{TeO}_{2}$ etc and alkali or silver oxides as modifiers. ${ }^{1,2}$ Thangadurai and Weppner ${ }^{3}$ stressed the importance of ionic conduction in cathode materials and have discussed the structural aspects of ionic conductors suitable for application in rechargeable batteries.

Alkali oxides added to network-forming glasses expand the region of glass formation and also modify the networks by creating non-bridging oxygens (NBOs) in the structure. These NBO's constitutes anionic sites with different binding energies to the alkali ions. These energies are indeed different and stronger than the bond energies of oxygens in the boron tetrahedra. Horopanitis et $\mathrm{al}^{4}$ pointed out that, the $\mathrm{Li}^{+}$transport in lithiated boron oxide glasses increases with $\mathrm{Li}_{2} \mathrm{O}$ concentration not only due to $\mathrm{Li}^{+}$ion concentration but also due to structural modification. Ion conducting glasses

\footnotetext{
*Author for correspondence (nivetejareddy @ gmail.com)
}

with high $\mathrm{Li}^{+}, \mathrm{Na}^{+}, \mathrm{Ag}^{+}, \mathrm{Cu}^{+}$and with very high values of conductivity are called fast ion conductors (FICs) and they are promising glassy electrolytes for the solid state batteries. $^{5-7}$ On the other hand, in glasses containing transition metal oxide (TMO) such as $\mathrm{V}_{2} \mathrm{O}_{5}, \mathrm{Fe}_{2} \mathrm{O}_{3}, \mathrm{CuO}, \mathrm{MoO}_{3}, \mathrm{WO}_{3}$, $\mathrm{CoO}$ etc, conduction arises from electrons known to be electronic semiconductors. The existence of both low and high valence states of transition metal ions (TMIs) is responsible for the electronic conduction in these glasses. ${ }^{8-10}$ Further, increase in the concentration of the modifier oxide has been found to have profound effect on transport, physical, chemical and optical properties of glasses. ${ }^{11-15}$ It is expected that transition metal oxide doped with alkali-modified glasses exhibit both ionic and electronic (polaronic) conduction. ${ }^{10,16}$ Generally, alkali-rich glasses exhibit dominant ion conductivity, while TMI-rich glasses exhibit dominant electronic conductivity. ${ }^{17,18}$

Conductivities in glasses containing vanadium oxide arise from the presence of $\mathrm{V}^{4+}$ and $\mathrm{V}^{5+}$. EPR spectra of $\mathrm{V}_{2} \mathrm{O}_{5}$ containing glasses also originates from $\mathrm{V}^{4+}$ paramagnetic centres, whose outer electronic structure $3 \mathrm{p}^{6}, 3 \mathrm{~d}^{1}$ enables unpaired magnetic moments of $3 \mathrm{~d}^{1}$ electrons to interact with the electromagnetic field in the microwave range, whereas the electronic structure of $\mathrm{V}^{5+}$ is $3 \mathrm{p}^{6}$, which has total electron spin zero. Since the $\mathrm{V}^{4+}$ ion has electronic spin $\mathrm{s}=1 / 2$ and nuclear spin of ${ }^{51} \mathrm{~V}$ is $\mathrm{I}=7 / 2$, one should expect interactions between corresponding magnetic moments resulting in 
the hyperfine structure. Gupta $e t a l^{19}$ pointed out that, long range electron spin-spin interactions between $\mathrm{V}^{4+}$ ions and the spin orbit coupling cause an anisotropy of the g-factor and the broadening of the individual lines. ${ }^{19,20}$ In glasses only orientation-averaged spectra can be observed, which can lead to additional reduction of hyperfine structure lines. It was seen in $\mathrm{V}_{2} \mathrm{O}_{5}-\mathrm{TeO}_{2}$ glasses that, the disappearance of hyperfine structure lines at higher contents of $\mathrm{V}_{2} \mathrm{O}_{5}$ is due to superexchange interaction of $\mathrm{V}^{4+}-\mathrm{O}-\mathrm{V}^{5+}$ chains. ${ }^{21}$ Physical property measurements like density and molar volume, thermal properties like $T_{\mathrm{g}}, \Delta T$, EPR studies of $\mathrm{V}^{4+}$ in the glasses and conductivities (both dc and ac) have been performed and the conductivity behaviour have been examined using the measured properties.

\section{Experimental}

Glasses were prepared by microwave heating technique using the general formula: $x \mathrm{~V}_{2} \mathrm{O}_{5} \cdot(100-x)\left[0.5 \mathrm{Na}_{2} \mathrm{O}\right.$ : $0.5 \mathrm{~B}_{2} \mathrm{O}_{3}$ ] (where $10 \leq x \leq 50$ ) using analar grade sodium carbonate $\left(\mathrm{Na}_{2} \mathrm{CO}_{3}\right)$, orthoboric acid $\left(\mathrm{H}_{3} \mathrm{BO}_{3}\right)$ and vanadium pentoxide $\left(\mathrm{V}_{2} \mathrm{O}_{5}\right)$ as starting materials. An appropriate quantity of weighed chemicals were mixed and thoroughly ground to homogenize the mixture and kept in a silica crucible inside a domestic microwave oven operating at $2.45 \mathrm{GHz}$ and at a tunable power level up to a maximum of $850 \mathrm{~W}$. Within 6-8 min of microwave exposure a good homogeneous melt was obtained, which was immediately quenched between copper blocks. The silica crucible was found to remain clean and unaffected during the short duration of melting. The glass was annealed in a muffle furnace for $1 \mathrm{~h}$ at $200^{\circ} \mathrm{C}$ to remove thermal strains that could have developed during quenching. The samples were preserved in a sealed desiccator containing $\mathrm{CaCl}_{2}$. Glass transition temperature $\left(T_{\mathrm{g}}\right)$ of the samples was recorded using differential scanning colorimeter (Perkin Elmer DSC-2). For the electrical measurements, the annealed samples were thoroughly polished and coated with silver paste on both sides, which serve as electrodes having a thickness of about $0.1 \mathrm{~cm}$ and diameter of about $1 \mathrm{~cm}$ were used. The resistivity of the sample was calculated by applying a $\mathrm{dc}$ field of $2 \mathrm{~V}$ and measuring the current through it using a digital electrometer (ECIL EA-5600). The temperature was measured using a chromel-alumel thermocouple placed very close to the sample. The measurements were repeated with changed polarity of the applied voltages. Capacitance $\left(C_{\mathrm{p}}\right)$ and conductance $(G)$ measurements were carried out on a Hewlett-Packard HP 4192A impedance-gain phase analyzer from $100 \mathrm{~Hz}$ to $10 \mathrm{MHz}$ in the temperature range 323-405 $\mathrm{K}$. A home-built cell assembly (having two terminal capacitor configuration and spring-loaded silver electrodes) was used for the measurements. The temperature was controlled using Heatcon (Bangalore 560090, India) temperature controller with an accuracy of $\pm 1 \mathrm{~K}$ achieved in the entire range of measurements. The temperature of the sample was measured using Pt-Rh thermocouple positioned very close to the sample.

\section{Results and discussion}

The X-ray diffraction spectra did not show any sharp peaks (figure 1) indicating that the samples were amorphous. The DSC thermograms from three different stoichiometries are indicated in figure 2. Glass transition temperatures $\left(T_{\mathrm{g}}\right)$ were extracted using the intersection of extended linear regions as shown in figure 2 and these values lie in the range 517-640 $\mathrm{K}$. The $T_{\mathrm{g}}$ values are comparable with a similar composition prepared by conventional melt quench method. ${ }^{21}$ The glass transition temperature reflects the variation of liquidus temperature, $T_{1}$ of the glass forming melt, which implied the empirical relation $T_{1} \approx(3 / 2) T_{\mathrm{g}} .{ }^{21}$ In the present system, $T_{\mathrm{g}}$ value increases with increasing $\mathrm{Na}_{2} \mathrm{O}$ mol\%. This increase in $T_{\mathrm{g}}$ can be attributed to the replacement of weaker $\mathrm{V}-$ $\mathrm{O}-\mathrm{V}$ linkages by strong $\mathrm{B}-\mathrm{O}-\mathrm{V}$ and $\mathrm{B}-\mathrm{O}-\mathrm{B}$ linkages. The dc conductivity of the same composition from different

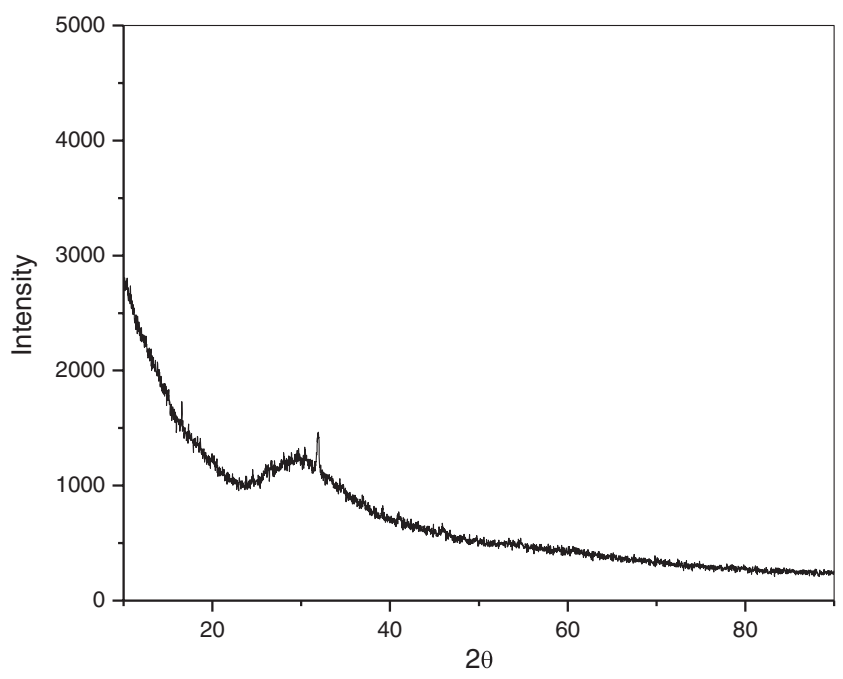

Figure 1. XRD spectrum of NBV9 glass.

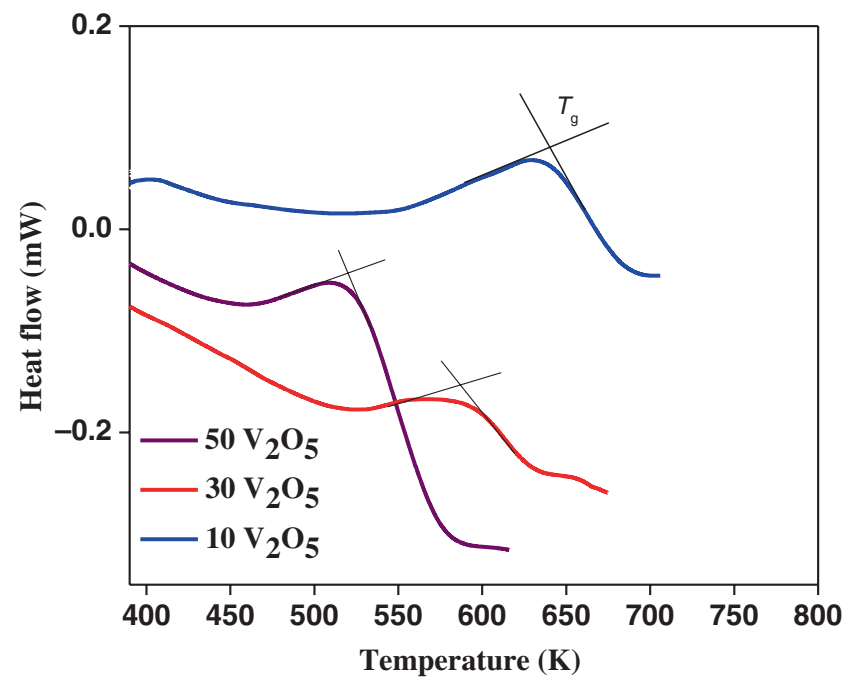

Figure 2. DSC thermogram of NBV glasses. 
batches prepared under identical conditions showed agreement within $5 \%$ error and dc conductivity on the same samples in different runs within $2 \%$ error. Figure 3 shows the variation of $\log (\sigma)$ as a function of inverse temperature for highly modified $r=0.111$ to 0.428 , where $r=$ $\mathrm{V}_{2} \mathrm{O}_{5} / \mathrm{Na}_{2} \mathrm{O}+\mathrm{B}_{2} \mathrm{O}_{3}$ and inset of figure 3 for least modified $r=0.538$ to 1 . The compositions of the glasses investigated and their codes are presented in table 1. It is seen from figure 3 that, the conductivity values lie in the range $1.02 \times$ $10^{-7}$ to $1 \times 10^{-5} \mathrm{~S} \mathrm{~cm}^{-1}$ for $r=0.111$. Also, it is seen from figure 3 that all the investigated samples follow Arrhenius law and the solid line represent the linear least square fits used to obtain the activation energy $\left(E_{\mathrm{dc}}\right)$. The values of $E_{\mathrm{dc}}$ lie in the range of 0.6 to $0.71 \mathrm{eV}$ and figure 4 represents the variation of $E_{\mathrm{dc}}$ with $r$, its inset represents the variation of $\log (\sigma)$ with $r$. Glasses with $r=0.111$ to 0.428 show a monotonic increase in $E_{\mathrm{dc}}$, then there is a gradual decrease from $r=0.528$ to 1 . Activation energies for $r=0.111$ to 0.428 are comparable with alkali borate glasses with low

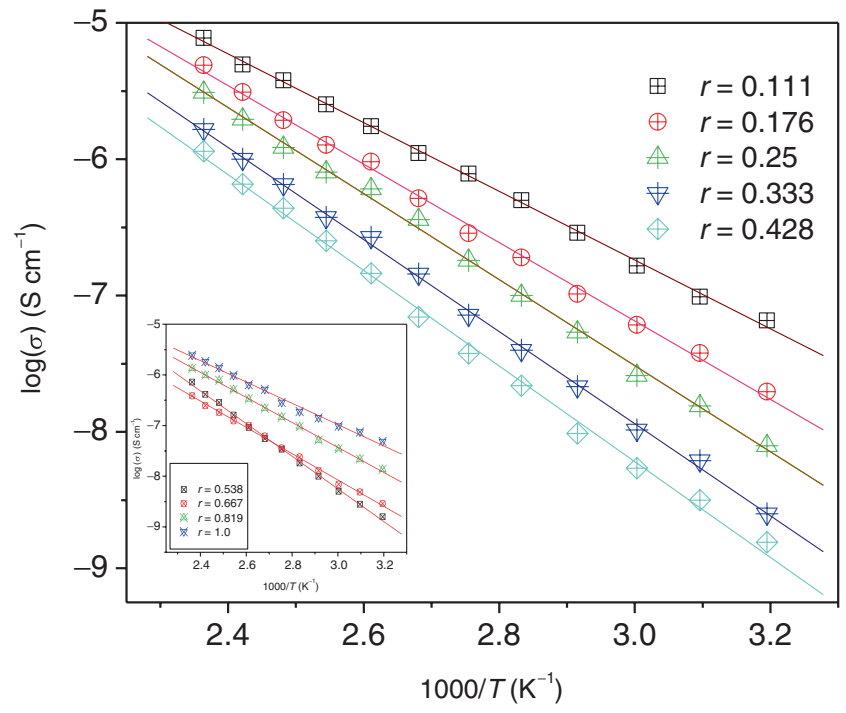

Figure 3. Variation of $\log (\sigma)$ with $1000 / T$ for $r=0.111$ to 0.428 in NBV glass system. Inset: Variation of $\log (\sigma)$ with $1000 / T$ for $r=0.538$ to 1.0 in NBV glass system.

Table 1. Code, composition and mole fraction of vanadium in sodium-boro-vanadate glass system.

\begin{tabular}{lcc}
\hline Code & $\begin{array}{c}\text { Composition }(\mathrm{mol} \%) \\
\mathrm{Na}_{2} \mathrm{O}: \mathrm{B}_{2} \mathrm{O}_{3}: \mathrm{V}_{2} \mathrm{O}_{5}\end{array}$ & $\begin{array}{c}\text { Mole fraction of } \\
\text { vanadium, } r\end{array}$ \\
\hline NBV1 & $25: 25: 50$ & 1.000 \\
NBV2 & $27.5: 27.5: 45$ & 0.818 \\
NBV3 & $30: 30: 40$ & 0.666 \\
NBV4 & $32.5: 32.5: 35$ & 0.538 \\
NBV5 & $35: 35: 30$ & 0.428 \\
NBV6 & $37.5: 37.5: 25$ & 0.333 \\
NBV7 & $40: 40: 20$ & 0.250 \\
NBV8 & $42.5: 42.5: 15$ & 0.176 \\
NBV9 & $45: 45: 10$ & 0.111 \\
\hline
\end{tabular}

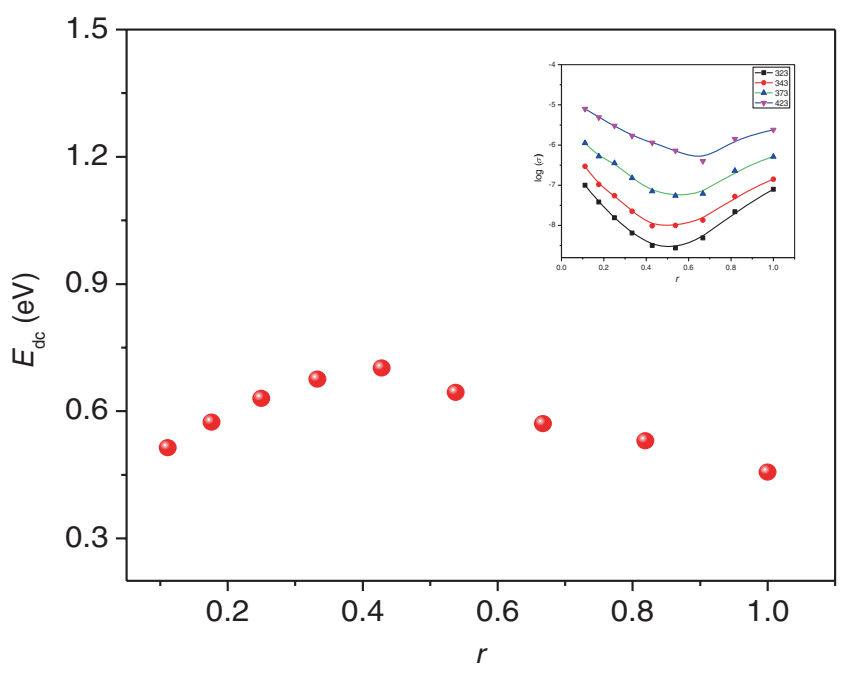

Figure 4. Variation of activation energy with mole fraction of $\mathrm{V}_{2} \mathrm{O}_{5}$ in NBV glass system. Inset: Variation of $\log (\sigma)$ with mole fraction of $\mathrm{V}_{2} \mathrm{O}_{5}$ in $\mathrm{NBV}$ glass system.

concentrations of TMO.$^{22}$ It can be seen from figure 4 inset that the conductivity shows a deep minimum at $r=0.538$. This may be due to the crossover from one conduction mechanism to another. The variations seen in dc conductivity are analysed using impedance spectroscopy and EPR studies.

\subsection{Impedance spectroscopy}

The impedance spectra of all the investigated glasses depend considerably on their chemical composition. The characteristic features of these spectra follow the nature of conduction mechanism. The experimental spectra (complex impedance representation) can be classified into three types (i) single semicircle with a low frequency spur, (ii) spectra consisting of two depressed semicircles and (iii) single semicircle without spur. The inclined straight line (spur) at the low frequency region could be the effect of mixed electrode and electrolyte interface. The magnitude of inclination in the straight line is related to the width of the relaxation time distribution. ${ }^{23}$

Conductance $(G)$ and capacitance $\left(C_{\mathrm{p}}\right)$ directly measured from the impedance bridge were used to compute the real and imaginary parts of impedance. The real and imaginary parts of impedance $Z^{\prime}$ and $Z^{\prime \prime}$ were computed using the relations given by Ross Macdonald. ${ }^{24}$ Typical impedance plots (ColeCole plots) are shown in figure 5, which were used for dc conductivity determination. Values of $Z^{\prime}$ (bulk resistance) corresponding to the intersection of low frequency side of the high frequency in the formula

$$
\sigma_{\mathrm{dc}}=\frac{d}{R A}
$$

where ' $d$ ' is the thickness of the sample, ' $R$ ' is the bulk resistance of the samples and ' $A$ ' the conducting area of crosssection of sample. $\sigma_{\mathrm{dc}}$ values lie in the range $1.3 \times 10^{-7}$ to $1.1 \times 10^{-5} \mathrm{~S} \mathrm{~cm}^{-1}$ (for $r=0.111$ ). These values are comparable with those presented in figure 3. Plots of $\log (\sigma)$ 


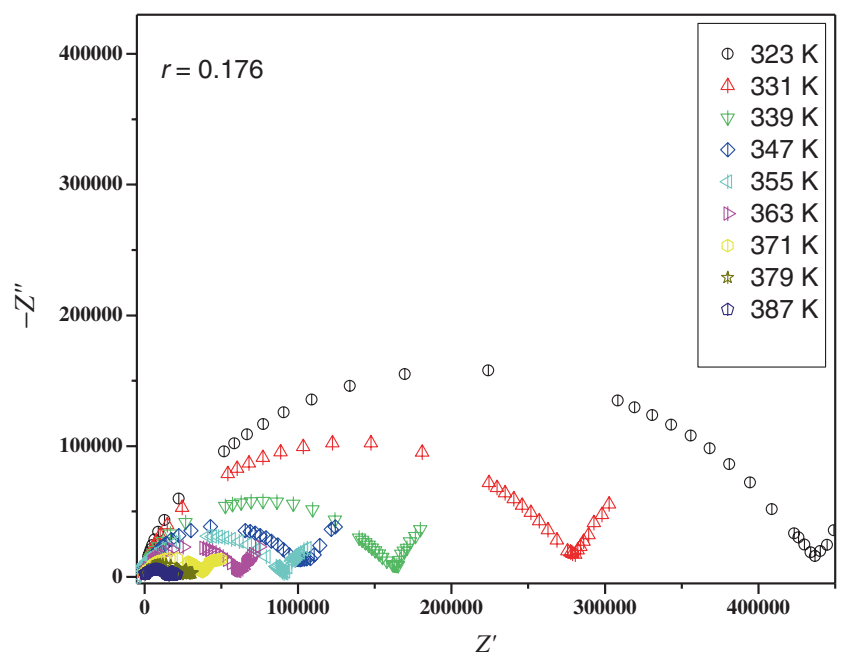

Figure 5. Typical Cole-Cole plot for NBV8 glass at different temperatures.

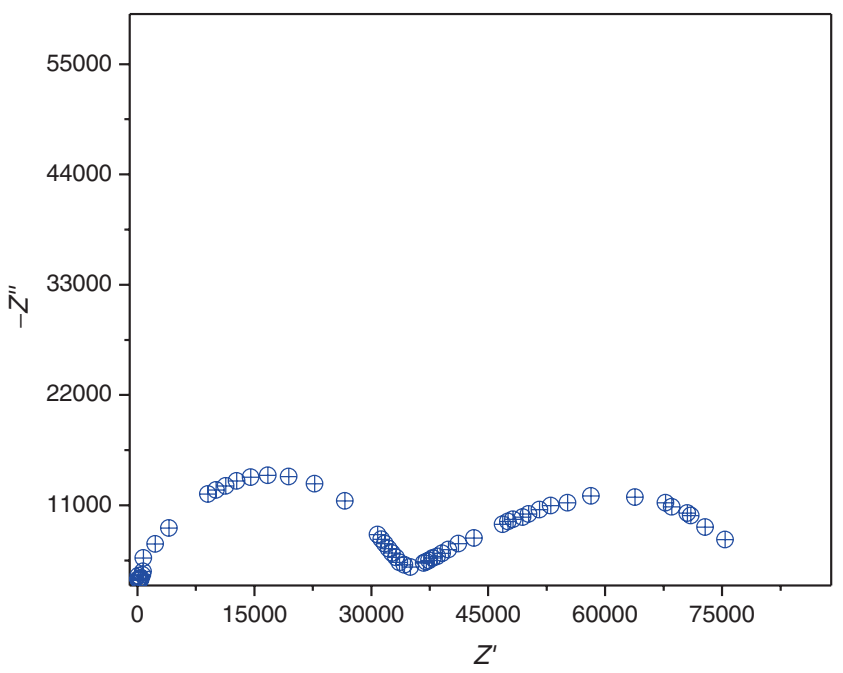

Figure 6. Typical impedance plot for NBV4 glass at $323 \mathrm{~K}$ temperature.

vs. 1000/T for all the investigated glasses follow Arrhenius law, and activation energies $\left(E_{\mathrm{dc}}\right)$ for various compositions are calculated using regression analysis. $E_{\mathrm{dc}}$ values lie in the range 0.57 to $0.715 \mathrm{eV}$ and are comparable with the activation energies shown in figure 4. Figure 6 shows impedance spectra of glass with $r=0.538$ showing two depressed semicircles, characteristic of mixed conduction. For $r>0.538$ single semicircles without any spur are seen. Garbarczyk et $a l^{17}$ reported that the simulated impedance spectra characteristic for ion conduction, mixed conduction and electronic conduction with the equivalent electrical circuits used to generate the spectra.

As can be seen from figure 4 inset, isothermal conductivity pass through a minimum at $r=0.538$. The presence of characteristic conductivity minimum and $E_{\mathrm{dc}}$ maximum is attributed to the enhanced interactions between polarons and mobile ions. ${ }^{25}$ At lower $r$ values, there is a reduction in the electronic component of conductivity due to the disruption of the glass network and increased population of $\mathrm{Na}^{+}$ions. Also a decrease in electronic conductivity is observed when $r$ decreases from 1 to 0.538 , which can be attributed to the reduction of $\mathrm{V}^{5+}$ to $\mathrm{V}^{4+}$ caused by the increase in $\mathrm{Na}_{2} \mathrm{O}$ content. The nonlinear variations can be interpreted using ionpolaron correlation effect. The hopping electron (polaron formed by its capture by a $\mathrm{V}^{5+}$ ) is attracted towards an oppositely charged $\mathrm{Na}^{+}$ion. The tendency for such cationpolaron pairs are to move together as a neutral entity. The migration of such an entity does not involve any net displacement of electric charge and does not contribute to conductivity. Eventually, there is an enhanced population of $\mathrm{Na}^{+}$ions in the network structure compared with trapped polarons. Thus, the cationic conductivity begins to increase. At $r=$ 0.538 , the interaction between electron-cation is maximum, suggesting a kind of transition from predominantly 'electronic' to 'ionic' conductivity. Hence, $r=0.538$ is considered to be the crossover composition. In the present study, we identified two regimes viz. highly modified 'ion' conducting and less modified 'electronically' conducting regimes. As discussed in the literature, alkali ion transport is characterized by high activation barrier. ${ }^{26,27}$ Further, electronic contribution to conductivity is significant as ionic contribution ${ }^{2}$ because

$$
\begin{aligned}
\sigma_{\text {total }} & =\sigma_{\text {ionic }}+\sigma_{\text {electronic }} \\
\log \sigma_{\text {total }} & =\log \left(\sigma_{\text {ionic }}+\sigma_{\text {electronic }}\right) \\
& =\log \left[\sigma_{\text {ionic }}\left(1+\frac{\sigma_{\text {elctronic }}}{\sigma_{\text {ionic }}}\right)\right] \\
& \approx \log \sigma_{0}-\frac{E_{\text {ionic }}}{k T}+\frac{\sigma_{\text {electronic }}}{\sigma_{\text {ionic }}}
\end{aligned}
$$

the ratio $\sigma_{\text {electronic }} / \sigma_{\text {ionic }}$ varies from glass to glass, since $\mathrm{Na}^{+} /\left[\mathrm{V}^{4+}\right]+\left[\mathrm{V}^{5+}\right]=\mathrm{Na}^{+} / V_{\text {total }}=r_{\mathrm{c}}$ varies. This ratio plays a pivotal role in nonlinear variation of conductivity. A similar trend is also seen in glasses containing both alkali oxide and TMO's. ${ }^{28-31}$ The conductivity reaches minima when the concentration of TMO is nearly equal to the concentration of $\mathrm{Na}_{2} \mathrm{O}$. The other possible explanation for the observed conductivity is that polaron percolation paths are blocked by alkali ions in alkali-rich glasses. ${ }^{28,31}$ More importantly, modifier to network former ratio can be effective if it is a measure of disruption of the glass network. If the ratio is higher, the glass network becomes more polymerized. In such a case the electron conduction paths are discontinuous. ${ }^{32}$ In $\mathrm{V}_{2} \mathrm{O}_{5}$-rich glasses $(r>0.538)$ conductivity increases, while the activation energy decreases (see figure 4) due to the abundance of vanadium in $\mathrm{V}^{4+}$ valance state. This results in higher value of redox ratio $C=\left[\mathrm{V}^{4+}\right] /\left[\mathrm{V}^{4+}\right]+\left[\mathrm{V}^{5+}\right]$, which is clearly reflected in EPR spectra.

\subsection{EPR spectroscopy}

EPR spectra of the investigated glasses are shown in figure 7. As can be seen from figure 7, a strong absorption line arises 


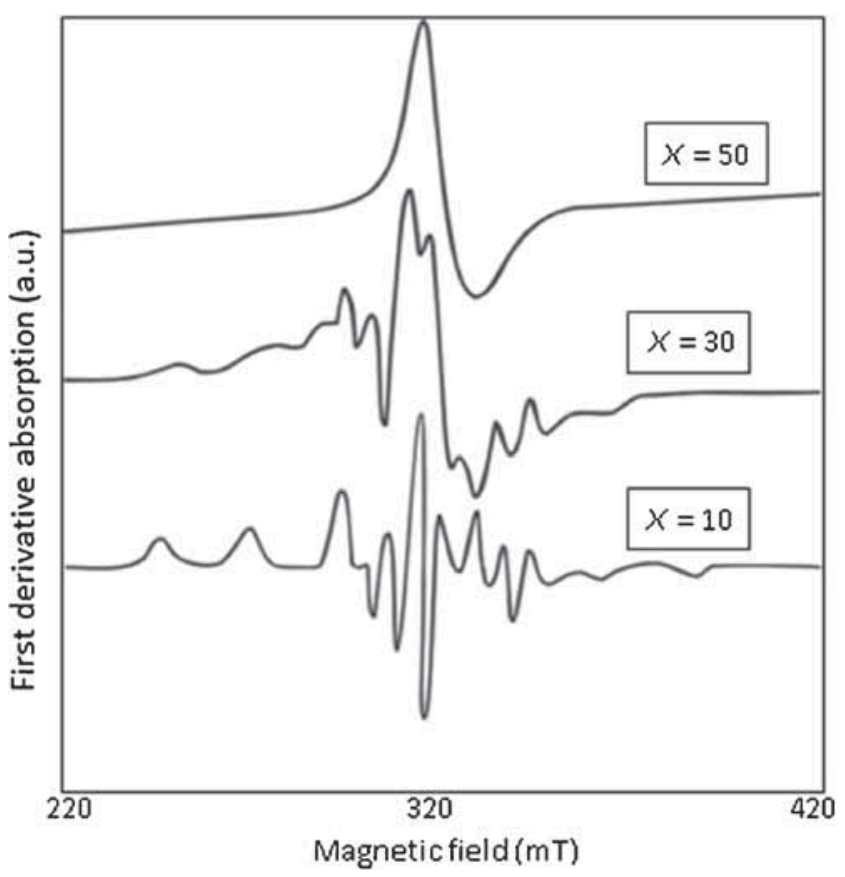

Figure 7. EPR spectra obtained at room temperature for NBV glass system with $\mathrm{V}_{2} \mathrm{O}_{5}$ mol\%.

from the fact that at high $\mathrm{V}_{2} \mathrm{O}_{5}$ content, most of the vanadium ions are in the $\mathrm{V}^{4+}$ state. The absence of hyperfine structure ( $\mathrm{hfs}$ ) points to interaction between vanadium centres via $\mathrm{V}^{4+}-\mathrm{O}-\mathrm{V}^{5+}$ super exchange mechanism. Generally, such glasses exhibit electronic conductivity. ${ }^{17}$ However, the mechanism of conduction in glasses with high concentration of $\mathrm{V}_{2} \mathrm{O}_{5}$ has been suggested as the transfer of an electron from $\mathrm{V}^{4+}$ site to a $\mathrm{V}^{5+}$ site.

Structural groups formed in $\mathrm{V}_{2} \mathrm{O}_{5}$-rich glasses provide the path for conduction of electrons. ${ }^{33}$ The increase of the electronic conduction with the increase of $\mathrm{V}_{2} \mathrm{O}_{5}$ can be explained considering the decrease in the average distance between the TMI sites. According to Mott's polaron theory, the dc conductivity rapidly varies with site spacing and redox ratio. The observed correlation between the mole fraction of alkali oxide and the appearance of hfs can be justified, taking into account that two nearest aliovalent vanadium centres can exchange an electron via bridging oxygen. The least modified network is characterized by a strongly crosslinked network. In such a network, the conditions for electron hopping via $\mathrm{V}^{4+}-\mathrm{O}-\mathrm{V}^{5+}$ bonds are more favourable than highly disrupted network. An illustration of transfer of electron from $\mathrm{V}^{4+}$ site to neighbouring $\mathrm{V}^{5+}$ site is shown in figure 8 . At $r=0.538$, the EPR spectra consists of $\mathrm{V}^{4+}$ line with a weak but visible superimposed hfs, which indicate the crossover from non-hfs regime to hfs regime. A similar crossover point is seen at this composition in the dc conductivity studies. Further, in highly modified glasses $(r=0.538)$ low content of $\mathrm{V}_{2} \mathrm{O}_{5}$ and high content of $\mathrm{Na}_{2} \mathrm{O}$ cause the disruption of the glass network. As a result cation $\left(\mathrm{Na}^{+}\right)$transport dominates the polaronic conduction. In such glass composition, ionic conduction paths consists of a regular disposition of NBO's

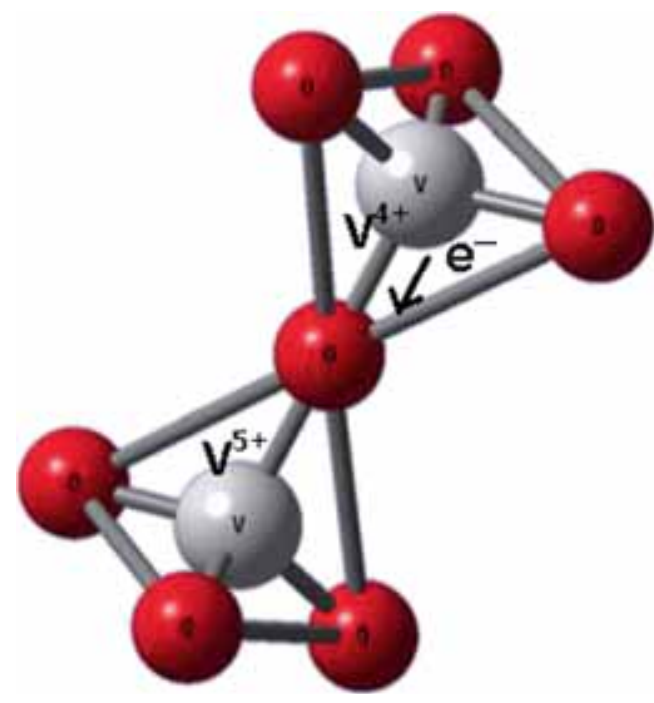

Figure 8. Illustration of transfer of electron from $\mathrm{V}^{4+}$ site to neighbouring $\mathrm{V}^{5+}$ site.

along the network-former chains, thereby allowing interstitial diffusion of ions. The network-modifying role of $\mathrm{Na}_{2} \mathrm{O}$ is explained using a simple structural model. $\mathrm{B}_{2} \mathrm{O}_{3}-\mathrm{V}_{2} \mathrm{O}_{5}$ glass is a continuous random network formed by $\left[\mathrm{BO}_{3 / 2}\right]^{0}$ and $\left[\mathrm{VOO}_{3 / 2}\right]^{0}$ structural units. Boron is three connected and three coordinated, while vanadium is three connected but four coordinated. Structural entities like boroxols that may be present in the structure are not significant for this model. Therefore, the network consists of B-O-B, B-O-V, V-O-B and $\mathrm{V}-\mathrm{O}-\mathrm{V}$ linkages depending upon the composition. All oxygen's, except the oxygen's in $\mathrm{V}=\mathrm{O}$ in the glass network, are bridging oxygens prior to modification. Addition of $\mathrm{Na}_{2} \mathrm{O}$ to a borovanadate network breaks the covalent bonds and converts bridging oxygen's (BO's) into NBO's, which of the bridges is broken by the reaction of $\mathrm{O}^{2-}$ is dictated by the local electron affinity for $\mathrm{O}^{2-}$ ions. Chemical affinity is controlled by the electronegativity of the network formers. The network-modifying action of $\mathrm{Na}_{2} \mathrm{O}$ can be explained as:

$$
\begin{array}{ll}
\mathrm{Na}_{2} \mathrm{O} \longrightarrow \mathrm{O}^{2-}+2 \mathrm{Na}^{+} \\
\mathrm{B}_{2} \mathrm{O}_{3} \equiv 2\left[\mathrm{BO}_{3 / 2}\right]^{0}, \quad \mathrm{~V}_{2} \mathrm{O}_{5} \equiv 2\left[\mathrm{VOO}_{3 / 2}\right]^{0} \\
2\left[\mathrm{BO}_{3 / 2}\right]^{0}+\mathrm{O}^{2-} \longrightarrow 2\left[\mathrm{BO}_{2 / 2} \mathrm{O}\right]^{-} \quad(2 \mathrm{BO} \text { 's and } 1 \mathrm{NBO})
\end{array}
$$

Similarly,

$$
2\left[\mathrm{VOO}_{3 / 2}\right]^{0}+\mathrm{O}^{2-} \longrightarrow 2\left[\mathrm{VOO}_{2 / 2} \mathrm{O}\right]^{-}(3 \mathrm{BO} \text { 's and } 1 \mathrm{NBO})
$$

An illustration of interstitial diffusion of $\mathrm{Na}^{+}$in the modified glass network is shown in figure 9.

\subsection{AC conductivity studies}

AC conductivities have been measured in the frequency range of $100 \mathrm{~Hz}$ to $10 \mathrm{MHz}$. A typical plot of $\log (\sigma)$ vs. $\log (f)$ 


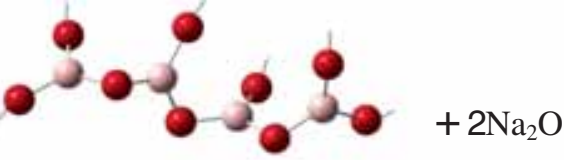

$4\left[\mathrm{BO}_{3 / 2}\right]^{0}$

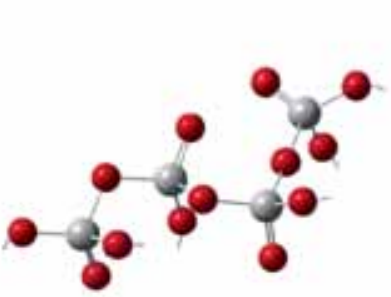

$4\left[\mathrm{VOO}_{3 / 2}\right]^{0}$

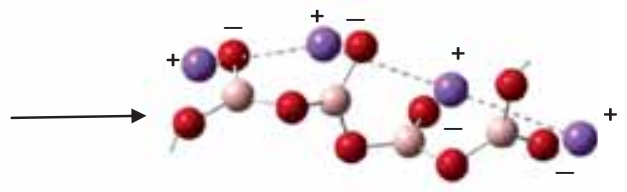

$4\left[\mathrm{BO}_{2 / 2} \mathrm{O}\right]^{-}$
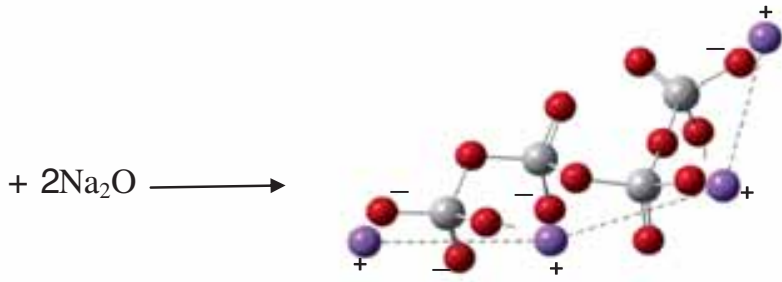

$4\left[\mathrm{VOO}_{2 / 2} \mathrm{O}\right]^{-}$

Boron,

Vanadium,

Bridging oxygen,

Non-bridging oxygen,

Sodium ion

Figure 9. Illustration of interstitial diffusion of $\mathrm{Na}^{+}$in the modified glass network.

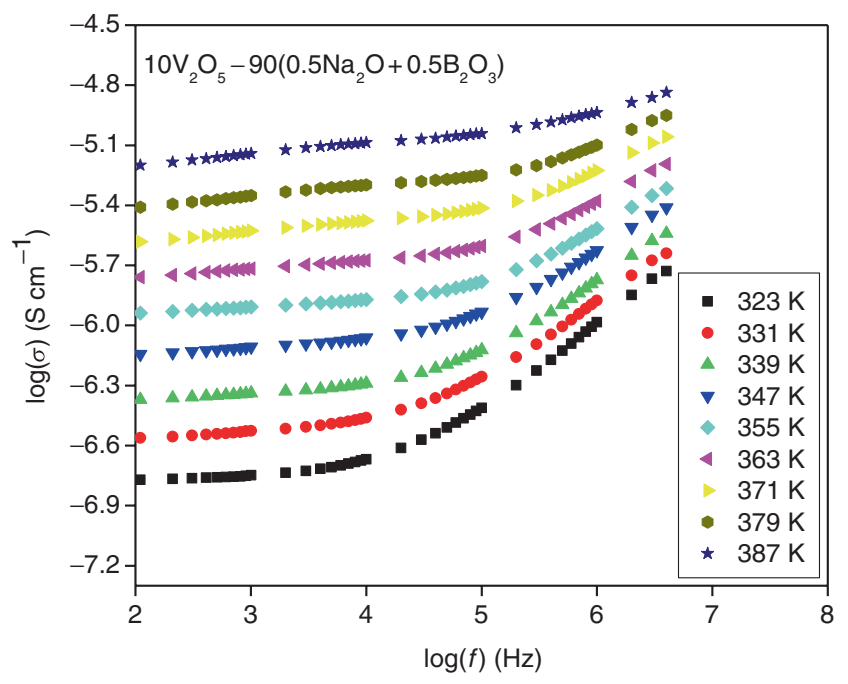

Figure 10. Variation of $\log (\sigma)$ with $\log (f)$ for NBV9 glass system.

is shown in figure 10 at various temperatures. All the samples performed high frequency dispersion and nearly flat frequency insensitive conductivities at low frequencies. The switchover from the frequency independent region to frequency dependent region signs the onset of conductivity relaxation, which shifts towards higher frequencies as the temperature increases. However, from figure 10, it is observed that the temperature dependence of the ac conductivity is much less than that of the dc conductivity. These conductivities have been fitted to the Almond-West type power law expression ${ }^{34,35}$

$$
\sigma(\omega)=\sigma(0)+A \omega^{s},
$$

Where $\sigma(0)$ is the frequency independent component of conductivity, $A \omega^{s}$ represent the dissipative contribution to the total conductivity depending on frequency $(\omega=2 \pi f)$, $A$ is the temperature dependant constant and $s$ the power law exponent. Nonlinear fit, which obeys Almond-West power law is shown in figure 11a. It has been reported in the literature that, better power law fits were obtained using expression of the type $\sigma(\omega)=\sigma(0)+A \omega^{s_{1}}+B \omega^{s_{2}}$, where $B$ is a constant, $s_{1}$ is the freely floated value $(=s)$ and $s_{2}=$ $1.0 .{ }^{34,35}$ The double power law fit is shown in figure $11 \mathrm{~b}$. Further, $s$ values have been obtained for all the glass samples at different temperatures using both two-term power law and three-term power law. The $s$ values lie in the range 0.4 to 0.7 and decreases with temperature. The important features of the power law analysis are (i) the two-term power law seems to be adequate in fitting the ac conductivity data and (ii) the values of $s$ are temperature dependent and less than unity. Although analysis of the power law exponent is limited by an inherent 'window effect', the observed power law exponent remains within the error $\pm 5 \%$ and render the window effect less important than it appears. ${ }^{36}$

However, in the essentially flat region dominated by ion transport appears to still consist of a non-negligible small temperature-dependant contribution from electron transport. This may be of the form $\sigma_{\mathrm{e}}=\sigma_{\mathrm{e}}(0) \exp (-\Delta E e / k T)$, where $\sigma_{\mathrm{e}}(0)$ and $\Delta E e$ are the corresponding pre-exponential and activation energy parameters. We have not attempted to analyse this feature any further.

\subsection{Electrical modulus formalism}

Electrical modulus is an alternative approach to investigate the complex electrical response of materials, which 

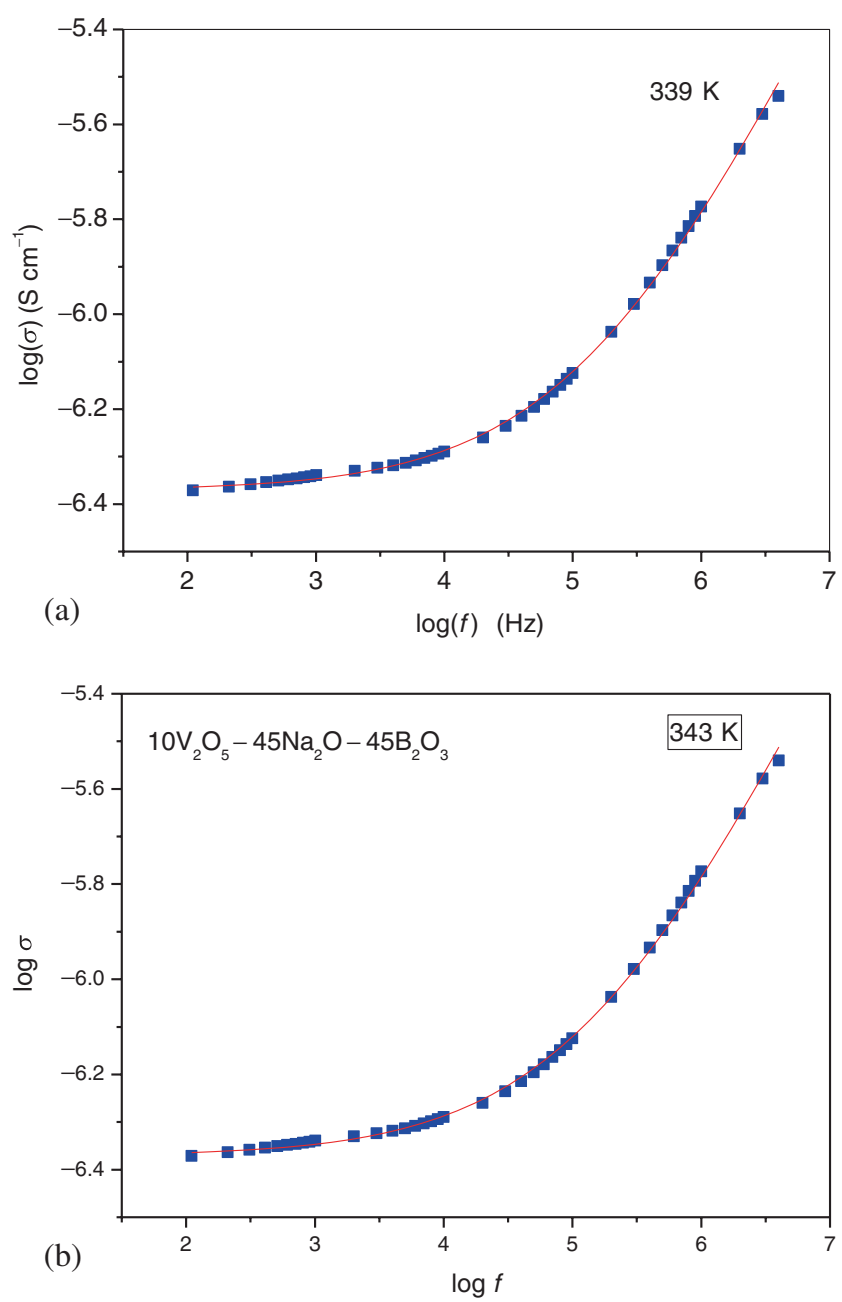

Figure 11. (a) Single power law fit $\left(\sigma(\omega)=\sigma(0)+A \omega^{s}\right)$ for NBV9 glass system. (b) Double power law fit $(\sigma(\omega)=\sigma(0)+$ $\left.A \omega^{s_{1}}+B \omega^{s_{2}}\right)$ for NBV9 glass system.

nullify the electrode polarization effect. The complex electrical modulus $M^{*}=M^{\prime}+J M^{\prime \prime}$ where $M^{\prime}$ and $M^{\prime \prime}$ are the real and imaginary parts of electrical modulus, respectively. ${ }^{2}$ The $M^{\prime}$ and $M^{\prime \prime}$ are calculated using the relations given by Koushik Majhi et al. ${ }^{37}$ Figure 12a represents the variation of $M^{\prime}$ vs. $\log (f)$. The electrical modulus spectra represent a measure of the distribution of ion energies in the network structure. $^{2}$ As seen from figure 12a, at higher frequencies, $M^{\prime}$ reaches a maximum constant value and at low frequencies $M^{\prime}$ approaches to zero, which indicates that the electrical polarization makes a negligible contribution. ${ }^{38}$ Further, dispersion between these frequencies is due to the conductivity relaxation. As seen from figure 12a the spectrum has a similar shape at all temperatures with a long tail. This may be attributed to the large capacitance associated with the electrodes. Figure $12 \mathrm{~b}$ shows the variation of $M^{\prime \prime} v s . \log (f)$ for $r=0.176$. It is seen from figure $12 \mathrm{~b}$ that $M^{\prime \prime}$ peak shifts to higher frequencies with increase temperature, suggesting the involvement of temperature-dependent relaxation process in the glasses under the present study. The $M^{\prime \prime}$ curves retain the same shapes but differ only in peak position and full-width at half maximum (FWHM) value. $M^{\prime \prime}$ vs. $\log (f)$ is generally
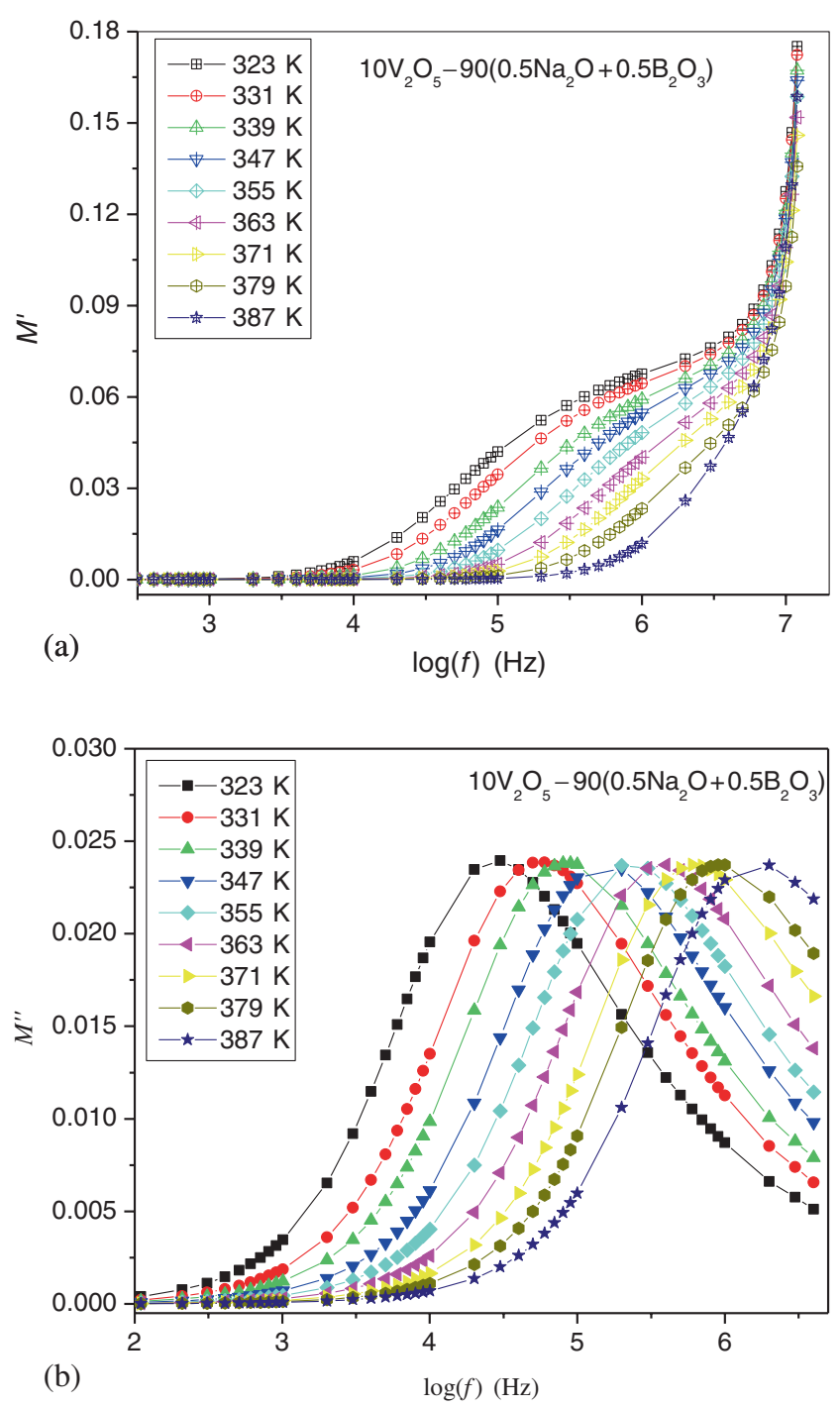

Figure 12. (a) Variation of real $M^{\prime}$ of the electric modulus with $\log (f)$. (b) Variation of imaginary $M^{\prime \prime}$ of the electric modulus with $\log (f)$.

analysed by using Kohlrausch-William-Watts (KWW) stretched exponential function. ${ }^{39,40}$ The approaches of Rao et $a l^{41}$ and Elliott et $a l^{42}$ were to establish the basis for stretched exponent $(\beta)$ in the relation $R(t)=R_{0} e^{-((t) / \tau)^{\beta}}$, where $R(t)$ and $R_{0}$ are the magnitudes of an appropriate parameter at times $t=t$ and $t=0$, respectively, $\tau$ is the fundamental relaxation time, $\beta$ is the stretched exponent and then to relate $\beta$ to $s$ through an assumed relation $s+\beta=$ 1. In diffusion-controlled relaxation process, ${ }^{40}$ microscopic relaxation time is modified as a result of interruption by random event which brings about instantaneous relaxation. Relaxation is assumed to take place in the neighbourhood of a vacancy in a model proposed by Rao $e t a l^{43}$ and is interrupted by a sudden arrival of an ion at the vacancy. Both the models lead to the same formal expression and provide a basis for $\beta$. The values of $\beta$ were determined by interpolating the FWHM values of $M^{\prime \prime}$ peaks into an expanded FWHM $v s$. $\beta$ maps generated from the literature. ${ }^{44} \beta$-Values 
lie in the range 0.5 to 0.6 and are almost temperature and composition insensitive, indicating that ion-ion interactions are independent of temperature and composition. ${ }^{4,46}$ The relaxation time characterizing the motion of an ion between equivalent positions is $\tau=\tau_{0} e^{E_{\mathrm{ac}} / k T}$, where $\tau_{0}$ is the preexperimental time, $E_{\mathrm{ac}}$ the ac activation energy and, $k$ the Boltzmann constant. The relaxation time values, $\tau$, symmetrically shift to higher values as the temperature increases (see figure $12 \mathrm{~b}$ ). The conductivity relaxation frequency $\omega_{\mathrm{c}}$ corresponding to the peak $\left(M_{\max }^{\prime \prime}\right)$ gives the characteristic relaxation time by the condition $\omega_{\mathrm{c}} \tau_{\mathrm{c}}=1 .^{47,48}$ The activation energy $\left(E_{\mathrm{ac}}\right)$ involved in the relaxation process of ions was calculated using temperature-dependent relaxation frequency. The values of $E_{\mathrm{ac}}$ lie in the range 0.61 to $0.705 \mathrm{eV}$ and found to be comparable with $E_{\mathrm{dc}}$. Figure 13 shows the variation of $M^{\prime \prime} / M_{\max }^{\prime \prime} v s$. $\log \left(f / f_{0}\right)$ at different temperatures. It is seen from figure 13, the superimposibility of the above variation at different temperatures are very good, suggesting a common relaxation mechanism in the glasses with

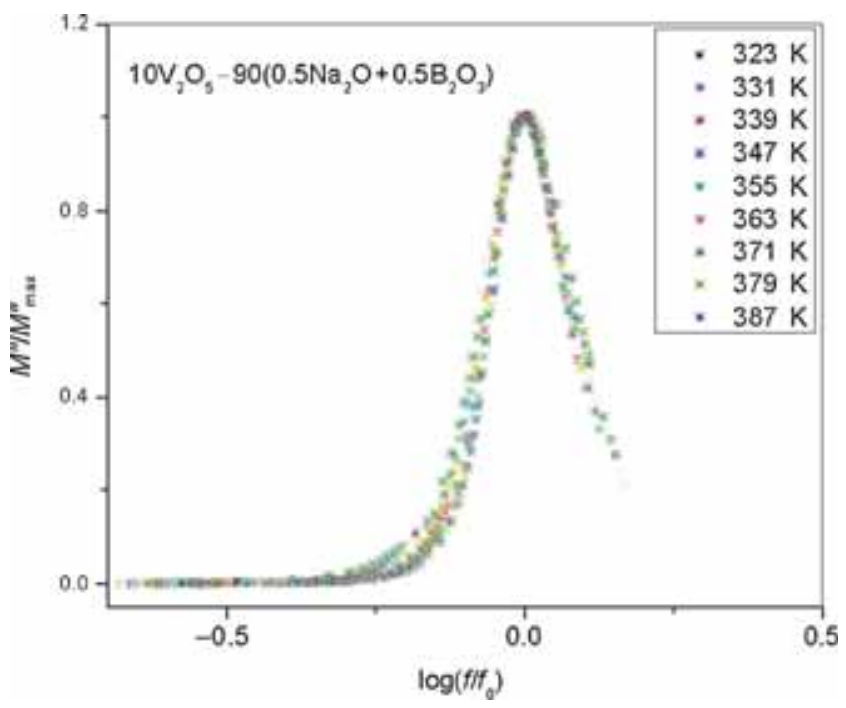

Figure 13. Variation of $\left(M^{\prime \prime} / M_{\max }^{\prime \prime}\right)$ with $\log \left(f / f_{0}\right)$.

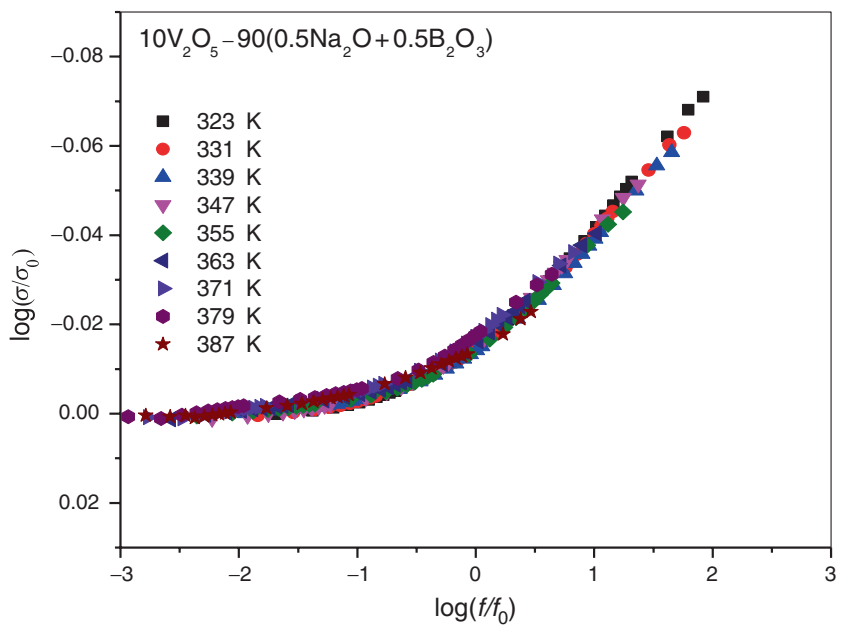

Figure 14. Variation of $\log \left(\sigma / \sigma_{0}\right)$ with $\log \left(f / f_{0}\right)$. $r=0.111$ to 0.428 for a given range of temperatures. ${ }^{49,50}$ The reduced plots of conductivity $(\log (\sigma / \sigma(0))) v s$. frequency $\left(\log \left(f / f_{0}\right)\right)$ are shown in figure 14 and the data points were scaled on to one master curve. It is seen from figures 13 and 14 that, the conductivity and dielectric relaxation data collapse excellently for the given range of temperatures. This suggests that the dynamical processes are temperature independent and good time-temperature superposition, indicating common ion transport mechanism in the highly modified glasses. ${ }^{51}$

\section{Conclusion}

The investigated glasses showed a nonlinear variation of electrical conductivity when 'electronically active' oxide $\left(\mathrm{V}_{2} \mathrm{O}_{5}\right)$ was substituted by the 'ionically active' network modifier $\left(\mathrm{Na}_{2} \mathrm{O}\right)$. Isothermal variation of dc conductivity as a function of $\mathrm{V}_{2} \mathrm{O}_{5}$ mole fraction $\left(r=\mathrm{v}_{2} \mathrm{O}_{\mathrm{s}} / \mathrm{Na}_{2} \mathrm{O}+\mathrm{B}_{2} \mathrm{O}_{\mathrm{s}}\right)$ passes through a minimum conductivity, wherein the conduction mechanism follows a crossover from 'ionic' to 'electronic'. Conductivity is predominantly ionic when $r$ lies between 0.111 and 0.428 , at $r=0.538$ shows a minimum conductivity, where the transition from ionic to electronic occurs and for $r>0.538$ electron transfer via aliovalent $\mathrm{V}^{4+}$ $-\mathrm{O}-\mathrm{V}^{5+}$ is more favourable. AC conductivity and electrical modulus formalism studies have been carried out for highly modified glasses ( $r=0.111$ to 0.428 ). Further, the ionic conductivity is analysed using Almond-West power law and KWW-stretched exponential function. The electrical modulus approach has been used to investigate the complex electrical response. Electrical modulus spectra reveals: (1) dispersion of $M^{\prime}$ over a range of frequencies is due to the conductivity relaxation, (2) $M^{\prime \prime}$ peak shifts for higher frequencies with increase in temperature, suggesting the involvement of temperature-dependent relaxation process and (3) values of activation energies involved in the relaxation process lie in the range 0.61 to $0.705 \mathrm{eV}$ and are comparable to activation energy $E_{\mathrm{dc}}$.

\section{Acknowledgements}

We are grateful to Professor KJ Rao, Solid State and Structural Chemistry Unit, Indian Institute of Science, Bangalore, for his encouragement and many helpful discussions. We also thank Jain University, Bangalore, for providing financial assistance to carry out this work.

\section{References}

1. Vaidhyanathan B, Raizada P and Rao K J 1997 J. Mater. Sci. Lett. 162022

2. Rao K J 2002 Structural chemistry of glasses (North-Holland: Elsevier)

3. Thangadurai V and Weppner W 2002 Ionics 8281 
4. Horopanitis E E, Perentzis G, Pavlidou E and Papadimitriou L 2003 Ionics 988

5. Angesh Chandra, Alok Bhatt and Archana Chandra $2013 \mathrm{~J}$. Mater. Sci. Technol. 29193

6. Das S S, Gupta C P and Vibha Srivastava 2005 Ionics 11423

7. Kabi S and Ghosh A 2013 Solid State Ionics. doi: 10.1016/j.ssi.2013.09.028

8. Muthupari S, Lakshmi Raghavan S and Rao K J 1996 J. Phys. Chem. 1004243

9. Mirzayi M and Hekmatshoar M H 2009 Ionics 15121

10. Jozwiak P and Garbarczyk J E 2005 Solid State Ionics 176 2163

11. Azmoonfar M, Hekmat-Shoar M H, Mirzayi M and Behzad H 2009 Ionics $\mathbf{1 5} 513$

12. Narayana Reddy C, Veeranna Gowda V C and Sujatha B 2006 Ionics 12159

13. Abbas L, Bih L, Nadiri A, El Amraoui Y, Mezzane D and Elouadi B 2007 J. Mol. Struct. 876194

14. Subrahmanyam K and Salagram M 2000 Opt. Mater. 15181

15. Sambasiva Rao K, Srinivasa Reddy M, Ravi Kumar V and Veeraiah N 2007 Physica B 39629

16. Mansour E, El-Egili K and El-Damrawi G 2007 Physica B 392 221

17. Garbarczyk J E, Murawski P, Wasiucionek M, Tykarski L, Bacewicz R and Aleksiejuk A 2000 Solid State Ionics 1361077

18. Subbalakshmi P and Veeraiah N 2002 J. Non-Cryst. Solids 298 89

19. Gupta S, Khanijo N and Mansingh A 1995 J. Non-Cryst. Solids 18158

20. Muncaster R and Parke S 1977 J. Non-Cryst. Solids 24399

21. Muthupari S, Prabakar S and Rao K J 1994 J. Phys. Chem. 98 2646

22. Sujata Sanghi, Anshu Sheoran, Ashish Agarwal and Satish Khasa 2010 Physica B 4054919

23. Barsoukov E and Macdonald J R 2005 Impedance spectroscopy: theory, experiment and applications. 2 ed. (New Jersey: Wiley- Interscience) p 303

24. Macdonald J R 1992 Ann. Biomed. Eng. 20289

25. Krins N, Rulmont A, Grandjean J, Gilbert B, Lepot 1, Cloots R and Vertruyen B 2006 Solid State Ionics 1773147

26. Nagaraja N, Sankarappa T and Prashant Kumar M $2008 \mathrm{~J}$. Non-Cryst. Solids 3541503

27. Krasowski K and Garbarczyk J E 1996 Physica Status Solidi (a) $158 \mathrm{~K} 13$
28. Murawski L and Barczynski R J 2005 Solid State Ionics 176 2145

29. Devidas G B, Sankarappa T, Chougule B K and Prasad G 2007 J. Non-Cryst. Solids 353426

30. Ungureanu M C, Levy M and Souquet J L 1998 Ionics 4200

31. Barczynski R J and Murawski L 2006 Mater. Sci. Poland 24 221

32. Bacewicz R, Wasiucionek M, Twarog A, Filipowicz J, Jozwiak P and Garbarczyk J 2005 J. Mater. Sci. 404267

33. Doweidar H, Megahed A and Gohar I A 1986 J. Phys. D: Appl. Phys. 191939

34. Almond D P, West A R and Grant R J 1982 Solid State Commun. 441277

35. Almond D P, Duncan G K and West A R 1983 Solid State Ionics $\mathbf{8} 159$

36. Sidebottom D L 1999 J. Non-Cryst. Solids 244223

37. Koushik Majhi, Rahul Vaish, Gadige Paramesh and Varma K B R 2013 Ionics 1999

38. Bose J M, Reau J M, Senegas J and Poulain M 1995 Solid State Ionics $\mathbf{8 2} 39$

39. Graham Williams and David C Watts 1970 Trans. Faraday Soc. 6680

40. Elliott S R 1988 Solid State Ionics 27131

41. Rao K J, Estournes C, Menetrier M and Levasseur A 1994 Philos. Mag. B 70809

42. Elliott S R and Henn F E G 1990 J. Non-Cryst. Solids 116 179

43. Rao K J Estournes C Levasseur A 1993 Philos. Mag. B 67 389

44. Sujatha B, Narayana Reddy C and Chakradhar R P S 2010 Philos. Mag. B 902635

45. Veeranna gowda V C, Chethana B K and Narayana Reddy C 2013 Mater. Sci. Eng. B $\mathbf{1 7 8} 826$

46. Manish S Jayaswal, Kanchan D K, Poonam Sharma and Meenakshi Pant 2011 Solid State Ionics 1867

47. Pant M, Kanchan D K, Sharma P and Manish S Jayswal 2008 Mat. Sci. Eng. 14918

48. Rahul Vaish and Varma K B R 2011 Ionics 17727

49. Munia Ganguli, Harish Bhat M and Rao K J 1999 Solid State Ionics $\mathbf{1 2 2} 23$

50. Sundeep Kumar, Murugavel S and Rao K J 2001 J. Phys. Chem. B 1055862

51. Veeranna gowda V C, Narayana Reddy C and Rao K J 2013 Bull. Mater. Sci. 3671 